\title{
Pediatric spinal injury in the US: epidemiology and disparities
}

\author{
Joseph H. Piatt Jr., MD \\ Nemours Neuroscience Center, A I duPont Hospital for Children, Wilmington, Delaware; and Departments of Neurological \\ Surgery and Pediatrics, Sidney Kimmel Medical College, Thomas Jefferson University, Philadelphia, Pennsylvania
}

\begin{abstract}
OBJECT In the US, race and economic status have pervasive associations with mechanisms of injury, severity of injury, management, and outcomes of trauma. The goal of the current study was to examine these relationships on a large scale in the setting of pediatric spinal injury.

METHODS Admissions for spinal fracture without or with spinal cord injury (SCI), spinal dislocation, and $\mathrm{SCl}$ without radiographic abnormality were identified in the Kids' Inpatient Database (KID) and the National Trauma Data Bank (NTDB) registry for 2009. Patients ranged in age from birth up to 21 years. Data from the KID were used to estimate nationwide annual incidences. Data from the NTDB were used to describe patterns of injury in relation to age, race, and payor, with corroboration from the KID. Multiple logistic regression was used to model rates of mortality and spinal fusion.
\end{abstract}

RESULTS In 2009, the estimated incidence of hospital admission for spinal injury in the US was 170 per 1 million in the population under 21 years of age. The incidence of SCI was 24 per 1 million. Incidences varied regionally. Adolescents predominated. Patterns of injury varied by age, race, and payor. Black patients were more severely injured than patients of other races as measured by Injury Severity Scale scores. Among black patients with spinal injury in the NTDB, 23.9\% suffered firearm injuries; only $1 \%$ of white patients suffered firearm injuries. The overall mortality rate in the NTDB was $3.9 \%$. In a multivariate analysis that included a large panel of clinical and nonclinical factors, black race retained significance as a predictor of mortality ( $p=0.006$; adjusted OR 1.571 [1.141-2.163]). Rates of spinal fusion were associated with race and payor in the NTDB data and with payor in the KID: patients with better insurance underwent spinal fusion at higher rates.

CONCLUSIONS The epidemiology of pediatric spinal injury in the US cannot be understood apart from considerations of race and economic status.

http://thejns.org/doi/abs/10.3171/2015.2.PEDS1515

KEY WORDS disparity; epidemiology; pediatric; SCIWORA; spinal cord injury; spinal dislocation; spinal fracture; spine; trauma

$\mathrm{I}$ $\mathrm{N}$ the US, race and economic status have pervasive associations with mechanisms of injury, severity of injury, management, and outcomes of trauma. Because trauma is the leading cause of death in childhood after the 1 st year, and because head injury is the leading cause of traumatic death, previous work has scrutinized the statistical relationships of race and economic status to the management of pediatric traumatic brain injury (TBI) $4,13,14,22,28$, $33,35,36,43,46,47,56,57$ The goal of this study was to extend this scrutiny to pediatric spinal injury.
The Kids' Inpatient Database (KID) is a compilation of de-identified discharge data from a sample of all hospital discharges of patients in the pediatric age range from community, nonrehabilitation hospitals in the US. The KID is prepared every 3 years by the Healthcare Utilization Project (HCUP) of the Agency for Healthcare Research and Quality in cooperation with participating states. Each version of KID includes roughly $10 \%$ of all discharges of uncomplicated in-hospital live births and roughly $80 \%$ of discharges of complicated births and other pediatric cases

ABBREVIATIONS AUC = area under the curve; GCS = Glasgow Coma Scale; ISS = Injury Severity Scale; KID = Kids' Inpatient Database; NTDB = National Trauma Data Bank; $\mathrm{SCI}=$ spinal cord injury; SCIWORA = SCI without radiographic abnormality; $\mathrm{TBI}=$ traumatic brain injury.

SUBMITTED January 8, 2015. ACCEPTED February 19, 2015.

INCLUDE WHEN CITING Published online June 26, 2015; DOI: 10.3171/2015.2.PEDS1515.

DISCLOSURE The author reports no conflict of interest concerning the materials or methods used in this study or the findings specified in this paper. 
from each sampled hospital. Each admission file incorporates 25 fields for ICD-9-CM diagnostic codes and 15 fields for ICD-9-CM procedure codes. The sampling is stratified and the files are weighted to allow extrapolation of incidences on a nationwide or regional basis or on the basis of hospital size, location, teaching status, or categorization by the National Association of Children's Hospitals and Related Institutions (NACHRI).

The National Trauma Data Bank (NTDB) is a registry that is organized and maintained by the American College of Surgeons Committee on Trauma. On an annual basis, it compiles discharge data from participating trauma programs. Verification as a trauma program is not required for institutional participation, but the majority of participating institutions are designated Level 1 or Level 2 trauma programs by the American College of Surgeons or by state agencies. At almost all participating institutions, data preparation and submission are supervised by dedicated, full-time trauma registrars. Like the KID, the NTDB includes ICD-9-CM diagnostic and procedure codes. Unlike the KID, the NTDB is a convenience sample and cannot be used for extrapolation of incidences on a population base.

Because the NTDB includes a great variety of clinical data not available in the KID, and because the KID includes demographic and financial data not available in the NTDB, parallel studies were performed using these 2 complementary data sets to provide a multifaceted picture of pediatric spinal trauma in the US.

\section{Methods}

The data for this study were taken from the 2009 KID and the 2009 NTDB. In both data sets, study cases were identified by ICD-9 codes for spinal fracture without spinal cord injury (SCI) (805.XX), spinal fracture with SCI (806.XX), spinal dislocation (839.00-839.59), and SCI without evidence of spinal osseous injury (952.XX). In the NTDB data set, a small number of additional cases were captured by search of Abbreviated Injury Scale "PreDot" codes. Only admissions of patients from 0 to 20 years of age were studied.

Nationwide population-based incidences were estimated from the KID using the weights provided in the data set (denominators for calculation of incidences were taken from the United States Census Bureau website [http:// www.census.gov/popest/data/historical/2000s/vintage 2009/index.html]). Other data reported from the KID reflect unweighted counts of cases, as do all the data reported from the NTDB.

Race is categorized differently in the KID and in the NTDB. The KID includes the categories white, black, Hispanic, Asian or Pacific Islander, Native American, and other. For purposes of this study, the last 3 categories were merged and designated "other." The NTDB has 2 fields for race with the following categories in each: white, black or African American, American Indian, other race, Native Hawaiian or other Pacific Islander, and Asian. In this study, only the first field was analyzed, and the last 5 categories were merged and designated "other." The NTDB has an additional field for designation of Hispanic or La- tino ethnicity. In this study, any file coded for Hispanic or Latino ethnicity was categorized as Hispanic for analysis of race, regardless of the original designation in the race field. Thus, the following categories were used in this study for analysis of race in both the KID data set and the NTDB data set: white, black, Hispanic, and other. Designation of race was missing from $16 \%$ of admissions in the 2009 KID as a matter of policy of the reporting state agencies in Minnesota, North Carolina, Ohio, and West Virginia. Because these data were absent on a nonrandom basis, extrapolation of nationwide incidences by race was not undertaken, and race was omitted from multivariate analysis of the KID.

Admissions ending in transfer to another acute care facility were excluded from further study to avoid double counting. Such transfers accounted for only $2.7 \%$ and $4.7 \%$ of cases from the NTDB and the KID, respectively.

Data organization and analysis were performed using SPSS 22.0 (IBM Corporation). Univariate associations of qualitative variables were analyzed by cross-tabulation and the chi-square statistic. Comparisons of proportions and confidence intervals for proportions were calculated using the normal approximation to the binomial distribution. None of the quantitative variables analyzed in this study were distributed normally, so nonparametric statistical tests were used for univariate comparisons. Where $p$ values have not been specified, denotation of significance implies $\alpha=0.05$.

Statistical models were constructed for an outcome (mortality) and for a process (spinal fusion). Multivariate analysis was conducted with logistic regression using the backward likelihood ratio method. Data were missing in small fractions of cases for a number of important variables. In the NTDB, payor was missing for $14.1 \%$ of admissions; disposition for 7.9\%; race for 3.1\%; Glasgow Coma Scale (GCS) motor score for 2.7\%; and Injury Severity Scale (ISS) score for $0.2 \%$. Variables with more than $20 \%$ missing data were not analyzed in the multivariate analysis. Values were imputed for variables with $2 \%-20 \%$ missing data, using the SPSS module for this purpose. Models were constructed in 2 blocks. Clinical predictors were in the first block; nonclinical predictors were in the second block. This construction allowed comparison of the relative importance of clinical and nonclinical factors, as reflected in the Nagelkerke $\mathrm{R}^{2}$ statistic. (Nagelkerke $\mathrm{R}^{2}$ is a measure of the portion of the variation of a response variable that can be explained by logistic regression. Like the more familiar coefficient of determination $\mathrm{R}^{2}$ from linear regression, it varies between 0 and 1.) The goal of the modeling was to explain as much variation as possible rather than to develop odds ratios for individual predictors. Thus, the criterion for entry of predictors was set at $\mathrm{p}$ $<0.10$, and the criterion for elimination of predictors was set at $p>0.20$. No predictors were held back because of anticipated multicolinearity. All predictors with univariate associations strong enough to be considered for entry were included. Systolic arterial pressure and ISS scores were included as quantitative predictors, but most other quantitative and categorical variables were dichotomized.

This study was exempted from supervision by the Nemours Delaware Valley Institutional Review Board. 


\section{Results}

From the KID data set, the estimated incidence of spinal injury of all kinds among patients in 2009 was 14,968 or 170 per 1 million in the population under 21 years of age. The incidence of SCI was 2139 or 24 per 1 million. The estimated nationwide age distributions of admissions for all spinal injuries and SCIs are presented in Fig. 1. Adolescents accounted for the preponderance of admissions in both categories. The population-based incidence of spinal injury and SCI was lowest in the Northeast and highest in the South. There were an estimated 418 deaths among patients with spinal injury for a rate of $2.8 \%$ and a population-based incidence of 5 per 1 million. Regional incidences of spinal injury, SCI, and death with spinal injury are presented in Table 1 . Including transfers to another acute facility, estimated total charges for hospital care of patients with spinal injury in the US in 2009 were $\$ 1.41$ billion.

In the NTDB data set, there were 12,438 admissions of patients younger than 21 years of age coded for spinal injury, so the NTDB captured roughly $83 \%$ of all admissions for spinal injury in the pediatric age group in the US in 2009. There were 1584 SCIs, or roughly $74 \%$ of all SCIs in this age group in the US in 2009, as estimated from the KID. Mechanisms, pathologies, and levels of injury by age group are presented in Table 2 for the NTDB. There were no gross discrepancies between the KID and the NTDB with respect to these factors (data not shown).

Mechanism and severity of injury had strong associations with race and economic factors. Table 3 presents associations between race and mechanism of injury in the
TABLE 1. Estimated incidences of spinal injury, $\mathrm{SCl}$, and death with spinal injury by region*

\begin{tabular}{lccc}
\hline \multicolumn{1}{c}{ Region } & Spinal Injury & SCl & Death With Spinal Injury \\
\hline Northeast & 147 & 20 & 3.35 \\
\hline Midwest & 182 & 25 & 6.58 \\
\hline South & 187 & 27 & 5.21 \\
\hline West & 165 & 22 & 3.83 \\
\hline
\end{tabular}

* Values are incidences per 1 million in the population under 21 years of age.

NTDB; associations in the KID were qualitatively similar and are not shown. Notable is the $23.9 \%$ prevalence of gunshot wounds among black patients admitted with spinal injury (21.6\% in the KID). Table 4 presents associations between payor and mechanism in the NTDB; again, associations in the KID were qualitatively similar and are not shown. The high prevalence of motor vehicle injuries among admissions with "other" payors suggests a substantial contribution from automobile insurance to this category. The KID contains a field for median income of home zip code by quartiles. Mechanism of injury is characterized on this basis in Table 5. Tables 4 and 5 depict socioeconomic relationships with injury: patients from wealthier neighborhoods with better insurance had more injuries related to bicycles, horses, and water activities than other patients. Patients from poorer neighborhoods with less insurance had more injuries related to firearms and abuse. Associations of ISS scores with payor and race from the NTDB are presented in Table 6. Among racial categories, black patients were most severely injured by

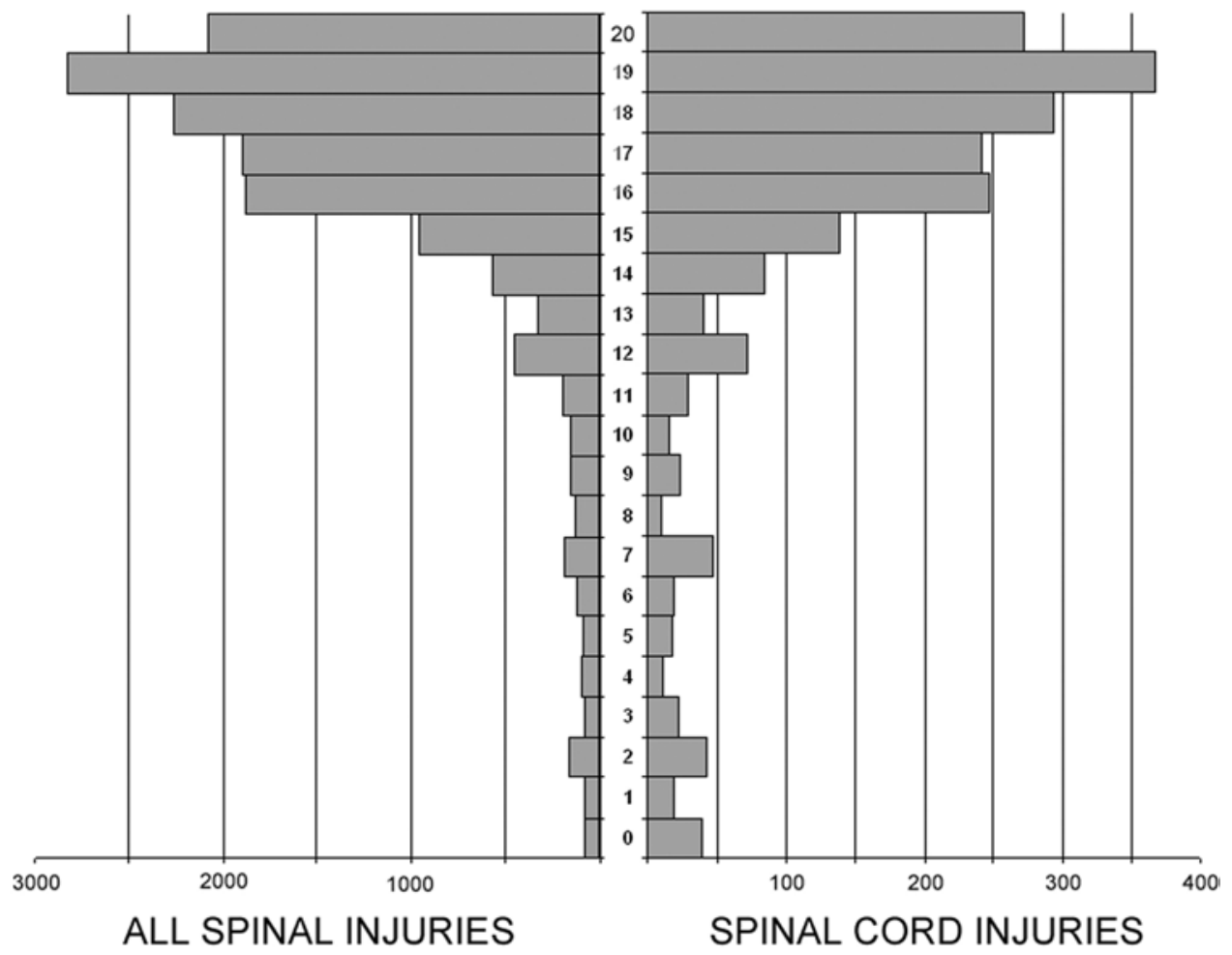

FIG. 1. Histograms depicting the estimated nationwide distribution by ages of admissions for spinal injury and SCI in 2009. In both categories, adolescents predominated, but infants and children accounted for a larger fraction of SCls than of all spinal injuries. 
TABLE 2. Mechanism of injury, pathology, and level of injury by age group in the NTDB*

\begin{tabular}{lccc}
\hline \multirow{2}{*}{ Characteristic } & \multicolumn{3}{c}{ No. of Admissions by Age Group (\%) } \\
\cline { 2 - 4 } Mechanism & $0-2$ Yrs & 3-12 Yrs & $13-20$ Yrs \\
\hline Motor vehicle & $101(42.1)$ & $683(52.2)$ & $7184(66.0)$ \\
\hline Fall & $70(29.2)$ & $346(26.4)$ & $1463(13.4)$ \\
\hline Firearm & $3(1.3)$ & $17(1.3)$ & $634(5.8)$ \\
\hline Horse & $0(0.0)$ & $28(2.1)$ & $116(1.1)$ \\
\hline Bicycle & $0(0.0)$ & $17(1.3)$ & $109(1.0)$ \\
\hline Water activities & $0(0.0)$ & $2(0.2)$ & $28(0.3)$ \\
\hline Abuse & $42(17.5)$ & $6(0.5)$ & $4(0.0)$ \\
\hline Other/unknown & $24(10.0)$ & $210(16.0)$ & $1350(12.4)$ \\
\hline Pathology & & & \\
\hline Fracture with SCI & $16(6.7)$ & $69(5.3)$ & $809(7.4)$ \\
\hline SCIWORA & $47(19.6)$ & $123(9.4)$ & $570(5.2)$ \\
\hline Dislocation & $56(23.3)$ & $195(14.9)$ & $708(6.5)$ \\
\hline Fracture without SCl & $140(58.3)$ & $1018(77.8)$ & $9758(89.6)$ \\
\hline Spinal level & & & \\
\hline C1-4 & $92(38.3)$ & $289(22.1)$ & $1580(14.5)$ \\
\hline C5-7 & $32(13.3)$ & $153(11.7)$ & $2005(18.4)$ \\
\hline Thoracic & $61(25.4)$ & $398(30.4)$ & $3567(32.8)$ \\
\hline Lumbosacral & $70(29.2)$ & $573(43.8)$ & $5686(52.2)$ \\
\hline Multiple levels & $47(19.6)$ & $232(17.7)$ & $2694(24.7)$ \\
\hline SCIORA spina cord inury & & & \\
\hline
\end{tabular}

SCIWORA = spinal cord injury without radiographic abnormality.

* A small fraction of cases ( $8.6 \%$ in the NTDB) had more than one ICD- 9 code for spinal injury.

this measure. Among categories of payors, patients with "other" insurance were most severely injured. As noted, the "other" insurance category was strongly associated with motor vehicle injuries. In the NTDB, SCI was most common among black patients and next most common among Hispanic patients; it was relatively less common among patients with "other" insurance (Table 7). Rates and statistical relationships were qualitatively similar in the KID, although the overall rate of SCI was slightly greater in the KID sample (14.5\% compared with $12.6 \%$ in the NTDB $[p<0.0005])$.

Many cases of spinal injury had concurrent head and

TABLE 3. Mechanism of injury by race from the NTDB*

\begin{tabular}{lcccc}
\hline \multirow{2}{*}{ Mechanism } & \multicolumn{4}{c}{ No. of Admissions (\%) } \\
\cline { 2 - 5 } & White & Black & Hispanic & Other \\
\hline Motor vehicle $\dagger$ & $5363(64.7)$ & $926(57.0)$ & $1069(68.5)$ & $486(66.3)$ \\
\hline Fall $\dagger$ & $1332(16.4)$ & $155(9.6)$ & $195(12.5)$ & $110(15.0)$ \\
\hline Firearm† & $83(1.0)$ & $388(23.9)$ & $134(8.6)$ & $38(5.2)$ \\
\hline Horse $\dagger$ & $123(1.5)$ & $0(0.0)$ & $12(0.8)$ & $7(1.0)$ \\
\hline Bicycle & $93(1.1)$ & $10(0.6)$ & $11(0.7)$ & $6(0.8)$ \\
\hline Water activities & $29(0.4)$ & $0(0.0)$ & $0(0.0)$ & $1(0.1)$ \\
\hline Abuse & $28(0.3)$ & $11(0.7)$ & $9(0.6)$ & $2(0.3)$ \\
\hline Other/unknown $\dagger$ & $1182(14.5)$ & $133(8.2)$ & $131(8.4)$ & $83(11.3)$ \\
\hline
\end{tabular}

* Table-wise Pearson chi-square $=1555.466, \mathrm{df}=21 ; \mathrm{p}<0.0005$.

$\dagger$ Rates differ significantly by race, with $p<0.05$ after Bonferroni correction.
TABLE 4. Mechanism of injury by payor from the NTDB*

\begin{tabular}{lccc}
\hline & \multicolumn{3}{c}{ No. of Admissions (\%) } \\
\cline { 2 - 4 } \multicolumn{1}{c}{ Mechanism } & Commercial & Other & $\begin{array}{r}\text { Public, Self-Pay, } \\
\text { or No Charge }\end{array}$ \\
\hline Motor vehicle & $2553(56.9)$ & $2048(81.9)$ & $2271(61.4)$ \\
\hline Fall & $924(20.6)$ & $163(6.5)$ & $517(14.0)$ \\
\hline Firearm & $106(2.4)$ & $77(3.1)$ & $380(10.3)$ \\
\hline Horse & $78(1.7)$ & $11(0.4)$ & $32(0.9)$ \\
\hline Bicycle & $62(1.4)$ & $9(0.4)$ & $30(0.8)$ \\
\hline Water activities & $15(0.3)$ & $8(0.3)$ & $3(0.1)$ \\
\hline Abuse & $9(0.2)$ & $2(0.1)$ & $35(0.9)$ \\
\hline Other/unknown & $739(16.5)$ & $182(7.3)$ & $429(11.6)$ \\
\hline
\end{tabular}

\footnotetext{
* Table-wise Pearson chi-square $=850.103, \mathrm{df}=14 ; p<0.0005$. For each individual mechanism, rates differ significantly by payor with $p<0.05$ after Bonferroni correction.
}

facial injuries. In the NTDB data set, $38.8 \%$ of cases with spinal injury were coded for TBI; $16.0 \%$ had GCS motor scores of $\leq 4$; and $10.2 \%$ had facial fractures. Conversely, among all cases in the NTDB younger than 21 years of age coded for TBI, 9.8\% had spinal injuries. Among all cases with GCS motor scores of $\leq 4,10.9 \%$ had spinal injuries. Among all cases coded for intubation or sedation in the emergency department, $16.7 \%$ had spinal injuries.

The overall mortality rate in the NTDB was $3.9 \%$. Among admissions in the NTDB with no code for TBI, the mortality rate was $1.0 \%$. The mortality rate in the KID sample was $2.8 \%(\mathrm{p}<0.0005)$. The overall rates of spinal fusion were $12.4 \%$ and $14.3 \%$ in the NTDB and the KID, respectively $(\mathrm{p}<0.0005)$. The median length of stay (LOS) was 4 days in both data sets, but the mean LOS was 8.01 days in the NTDB and 7.66 days in the KID ( $\mathrm{p}=$ 0.021 ). Rates of mortality and spinal fusion in the NTDB are analyzed with respect to associations with race and payor in Table 8.

In the multivariate model of mortality in the NTDB data set, the following predictors were retained in the final 2-block model: infant age, sex, partial SCI, fracture with-

TABLE 5. Mechanism of injury by median income of home zip code quartile from the KID*

\begin{tabular}{lcccc}
\hline & \multicolumn{4}{c}{ No. of Admissions (\%) } \\
\cline { 2 - 5 } \multicolumn{1}{c}{ Mechanism } & $\begin{array}{c}\text { Quartile 1 } \\
\text { (lowest) }\end{array}$ & Quartile 2 & Quartile 3 & $\begin{array}{c}\text { Quartile 4 } \\
\text { (highest) }\end{array}$ \\
\hline Motor vehicle & $1643(58.0)$ & $1558(57.7)$ & $1351(56.7)$ & $1056(50.8)$ \\
\hline Fall & $307(10.8)$ & $371(13.7)$ & $368(15.5)$ & $437(21.0)$ \\
\hline Firearm & $208(7.3)$ & $112(4.1)$ & $64(2.7)$ & $28(1.3)$ \\
\hline Horse & $20(0.7)$ & $25(0.9)$ & $31(1.3)$ & $32(1.5)$ \\
\hline Bicycle & $11(0.4)$ & $21(0.8)$ & $27(1.1)$ & $38(1.8)$ \\
\hline Water activities & $4(0.1)$ & $8(0.3)$ & $6(0.3)$ & $12(0.6)$ \\
\hline Abuse & $14(0.5)$ & $8(0.3)$ & $6(0.3)$ & $5(0.2)$ \\
\hline Sports & $24(0.8)$ & $21(0.8)$ & $23(1.0)$ & $47(2.3)$ \\
\hline Other/unknown & $601(21.2)$ & $575(21.3)$ & $505(21.2)$ & $424(20.4)$ \\
\hline
\end{tabular}

* Table-wise Pearson chi-square $=299.529, \mathrm{df}=24 ; p<0.0005$. For all mechanisms except "abuse" and "other/unknown," rates differ significantly by quartile, with $p<0.05$ after Bonferroni correction. 
TABLE 6. ISS scores by payor and race from the NTDB

\begin{tabular}{lc}
\hline \multicolumn{1}{c}{ Variable } & Median ISS (interquartile range) \\
\hline Payor $^{*}$ & \\
\hline Public, self-pay, no charge & $14(9-24)$ \\
\hline Other & $17(9-26)$ \\
\hline Commercial & $13(8-22)$ \\
\hline Race & \\
\hline White & $14(9-22)$ \\
\hline Black & $16(9-26)$ \\
\hline Hispanic & $14(9-26)$ \\
\hline Other & $14(9-25)$ \\
\hline
\end{tabular}

${ }^{*}$ Kruskal-Wallis; $p<0.0005$.

out SCI (protective), fracture with SCI (protective), spinal cord injury without radiographic abnormality (SCIWORA) (protective), high cervical injury, low cervical injury, thoracic injury (protective), multiple injury levels, GCS motor score $\leq 4$, any TBI, facial fracture (protective), mechanism (abuse, gun, and motor vehicle), systolic blood pressure, ln(ISS), self-transport, in-transfer (protective), and number of trauma registrars (protective). Addition of the second block improved the model only slightly: the Nagelkerke $\mathrm{R}^{2}$ improved from 0.511 to 0.517 . Thus, nonclinical factors contributed little to the model. The area under the receiveroperator characteristic curve for the 2-block model was 0.956 . The model performed well for black patients with an area under the curve (AUC) of 0.934 (0.914-0.954), but it performed better for patients of other racial categories with an AUC of 0.960 (0.950-0.960). When dichotomized variables for racial categories were added to the 2-block model, only the predictor black race retained significance ( $\mathrm{p}=0.006$; adjusted OR 1.571 [1.141-2.163]).

The model of spinal fusion was limited to admissions that ended in live discharge. Again, addition of nonclinical factors increased the Nagelkerke $\mathrm{R}^{2}$ of the model only slightly, from 0.275 to 0.281 . The following factors were retained in the final 2-block model: teen age, partial SCI,

TABLE 7. Rates of $\mathrm{SCl}$ as a percentage of all spinal injuries by race and payor from the NTDB

\begin{tabular}{lc}
\hline \multicolumn{1}{c}{ Variable } & No. of SCl Admissions (\%) \\
\hline Race & \\
\hline White & $816(10.9)$ \\
\hline Black & $289(19.6)^{*}$ \\
\hline Hispanic & $207(14.3) \dagger$ \\
\hline Other & $83(12.0)$ \\
\hline Payor & $524(12.7)$ \\
\hline Commercial & $232(9.9) \ddagger$ \\
\hline Other & $466(13.7)$ \\
\hline Medicaid, self-pay, no charge
\end{tabular}

* Rate for black patients significantly different from all other racial categories with Bonferroni correction.

† Rate for Hispanic patients significantly different from white and black patients with Bonferroni correction.

$\ddagger$ Rate for other insurance significantly different from all other categories with Bonferroni correction.
TABLE 8. Mortality rates and spinal fusion rates by race and payor from the NTDB

\begin{tabular}{lcc}
\hline \multirow{2}{*}{ Variable } & \multicolumn{2}{c}{ No. of Admissions (\%) } \\
\cline { 2 - 3 } Race & Mortality & Spinal Fusion \\
\hline White & $262(3.5)$ & $985(13.2)$ \\
\hline Black & $91(6.2)^{*}$ & $59(10.8)$ \\
\hline Hispanic & $57(3.9)$ & $162(11.2)$ \\
\hline Other & $22(3.2)$ & $75(10.8)$ \\
\hline Payor & & \\
\hline Commercial & $123(3.0) \dagger$ & $583(14.1) \ddagger$ \\
\hline Other & $87(3.7)$ & $248(12.1)$ \\
\hline Medicaid, self-pay, no charge & $150(4.4) \dagger$ & $378(11.1) \ddagger$ \\
\hline
\end{tabular}

* Pairwise differences between black race and each other racial category significantly different with Bonferroni correction.

$\dagger$ Pairwise difference significant with Bonferroni correction.

‡ Pairwise difference significant with Bonferroni correction.

complete SCI, spinal fracture, spinal fracture with SCI, spinal dislocation, $\ln (\mathrm{ISS})$, low cervical injury, thoracic injury, multiple injury levels (protective), TBI, facial fracture (protective), injury by fall, injury by gun (protective), in-transfer, arrival by helicopter, and public insurance as a dichotomized predictor (protective; $\mathrm{p}=0.034$, adjusted OR 0.860 [0.747-0.989]). Race as a 4-category predictor did not retain significance, nor did black race as a dichotomized variable substituted for race. White race substituted in the second block as a dichotomized variable retained marginal significance $(\mathrm{p}=0.051$; adjusted OR 1.162 [0.999-1.351]). Because of the strong correlation between race and payor, addition of white race to the model diminished the significance of public insurance $(p=0.076$; adjusted OR 0.879 [0.763-1.014]). Conversely, payor as a 3-category predictor substituted for public insurance did not retain significance when included in the second block with white race, which was significant at a $p$ value of 0.023 (adjusted OR 1.188 [1.024-1.378]).

To confirm the association of economic status with fusion rates, a parallel analysis was performed in the KID. Because designation of race was missing in $16 \%$ of cases on a nonrandom, state-wise basis, race was not included in the model. Other missing data were imputed. Again, a 2-block model was constructed. Addition of the nonclinical factors increased the Nagelkerke $\mathrm{R}^{2}$ of the model from 0.259 to 0.276 . The following predictors retained significance: teen age, spinal dislocation, spinal fracture, spinal fracture with SCI, low cervical injury, thoracic injury (protective), lumbosacral injury (protective), multiple injury levels, open injury (protective), injury by fall (protective), injury by firearm/abuse (protective), facial fracture (protective), TBI (protective), teaching hospital, small hospital (protective), and elective admission. As in the NTDB data set, public insurance (including self-pay and no charge) retained significance (protective; $p<0.0005$; adjusted OR 0.780 [0.703-0.866]).

\section{Discussion}

This report represents the first population-based study 
of spinal injury in childhood in the US. Because it drew from both a governmental administrative database and a large trauma registry, it offers a stereoscopic view of its subject. The KID was used for calculation of nationwide incidences. Because the NTDB registry contains more clinical detail, it was the principal source of data for statistical analysis of patterns of injury and outcomes. The KID contains a narrower set of clinical variables, but it offers descriptors of access that are not available in the NTDB. It also includes a small number of elective admissions for spinal injury. Whenever its data supported parallel analysis, the KID provided qualitative confirmation of the findings from the NTDB.

Mechanisms of spinal injury and anatomical patterns of injury have been described in many institutional case series and trauma registries, and the current study confirms these observations on a large scale. 1,6,9-12,15,16,18,20,26,31,39,41,44,49,50 Notable are frequent associations with head and facial injury, high rates of injury at multiple levels of the spine, the predominance of high cervical injury in the youngest patients, and the relatively high rate of SCIWORA in that age group. Injuries of the thoracic and lumbosacral spine have received relatively scant attention in the literature, but in the cross-sectional survey reported here, these levels account for more than half of all injuries in every age group.

Several other groups have also investigated pediatric spinal injury in registries and population-based data sets. ${ }^{7,21,34,38}$ In the UK Trauma Audit \& Research Network Database, Martin et al. noted that polytrauma and chest injuries were associated with spinal fracture-dislocation and with SCI. ${ }^{34}$ TBI with low GCS scores was associated with SCI. Mohseni et al. have documented the relationship between age and level of cervical spine injury using 5 years of data from the NTDB. ${ }^{38}$ Hagen et al. studied trends in the age-adjusted incidence of traumatic pediatric SCI over a 50-year period in Norway. The incidence among adolescents increased over time..$^{21}$ The overall rate among adolescents was 25.1 per 1 million per year, roughly 10 times the incidence in younger children. Chien et al. conducted a study of pediatric spinal injury at all levels over an 11-year period in Taiwan. ${ }^{7}$ They documented an overall annual incidence of SCI of 59.9 per 1 million. SCI was most common among adolescents and among children from lower socioeconomic strata.

Much has been written about the prevalence of spine injury in the setting of polytrauma, particularly in the unevaluable patient with TBI. ${ }^{17,25,27,32,37,42,52}$ Reported rates of cervical spine injury concomitant with traumatic coma are between $6 \%$ and $9 \%$. Lower rates have been cited in reports that detail less precisely the severity of the TBI and the methods of evaluation. ${ }^{3,40,54}$ In infancy, excepting cases of abusive head injury, the rates of spinal injury associated with TBI have seemed to be quite low., ${ }^{2,19,30}$ The current study reports spinal injury rates of $9.8 \%$ for NTDB admissions coded for TBI and $10.9 \%$ for admissions coded for GCS motor $\leq 4$, but all spinal levels have been counted. Among admissions of patients whose clinical evaluations were obscured by intubation or sedation, the current study notes a prevalence of spinal injury of $16.7 \%$.

There are fewer data about the obverse question, the prevalence of TBI among patients with spinal injury. In an institutional series of admissions of cervical spine injuries of all degrees of severity, Michael et al. noted coincident head injuries of all degrees of severity in $25 \%$ of patients. ${ }^{37}$ Iida et al. reported moderate or severe head injury in 35\% of 188 patients with cervical spine or SCI. ${ }^{29}$ In a study of spinal injuries at all levels limited to the pediatric age group, Cirak et al. recorded a $37.4 \%$ prevalence of TBI. ${ }^{9}$ In the current study, coincident TBI and GCS motor $\leq 4$ are noted in $38.8 \%$ and $16.0 \%$ of cases, respectively.

This study presents new information about patterns and severities of spinal injury among pediatric patients in differing racial and economic categories. ISS scores were highest among black patients and among patients with Medicaid or no insurance. Patients in these categories had startling rates of firearm-related injury, $23.9 \%$ and $10.3 \%$, respectively. Black patients also had the highest rates of SCI. Like other traumatic conditions, the epidemiology of pediatric spinal injury in the US cannot be understood apart from considerations of race and economic status.

Having demonstrated that patients of different racial and economic categories sustain qualitatively and quantitatively different injuries, a second goal of this investigation was to exploit the detail of the NTDB to determine whether differences in clinical and nonclinical factors explain the observed differences in outcome. In my judgment, the only credible functional outcome in the NTDB data set was mortality. Discharge to home might have been considered a marker of favorable outcome, but the data set did not distinguish patients who were discharged directly home after acute care from patients who were discharged to home after inpatient rehabilitation in the same institution as the acute care. The data set also did not distinguish transfer for rehabilitation from transfer for long-term care. Fortunately for the patients but unfortunately for the statistical analysis, mortality rates were quite low, and most deaths were related to head injury. Nevertheless, the number of cases was large enough to develop an informative multivariate statistical model. The only economic predictor, payor, was eliminated at an early stage of the second block of the regression. The final 2-block model had a high AUC for black patients, but the AUC was distinctly better for patients in other racial categories. Black race as a predictor retained significance when it was added to the 2-block model. In this analysis, black race entailed an added risk of mortality not explained by a large panel of clinical and access predictors. As the following discussion demonstrates, this result was expected.

If prehospital clinical and nonclinical factors cannot account for disparities in outcomes, the next logical question is whether patients in different racial and economic categories receive different treatment. Analysis of both the NTDB and the KID yielded affirmative answers. Because race and payor are so highly correlated, their associations with fusion rates were impossible to dissect apart in the NTDB. White children underwent more fusions; children with public insurance underwent fewer fusions. Race could not be analyzed in the KID, but the association of public insurance with lower fusion rates was confirmed. Statistical association is not causation. One possible explanation of these findings is the failure of the study databases to capture sufficient clinical data. Important but 
obscure clinical factors may covary with race and payor. Alternatively, as the indications for spinal fusion are not clearly defined in every clinical circumstance, the decisions of surgeons or families may be influenced by social or financial factors. Also unclear from the current analysis is whether the demonstrated disparities reflect overtreatment of one group or undertreatment of the other.

The current report adds to the large and growing body of evidence that race and economic status are determinants of trauma outcomes, above and beyond their identifiable associations with severity of injury and access to care. This topic has been reviewed recently. ${ }^{5,23}$ Race and economic status are highly correlated in the US, and studies have reached varying conclusions about the relative importance of these factors to trauma outcomes.

Of particular relevance to the current investigation are studies of pediatric trauma. There is general agreement that economic status, as measured by insurance coverage or median income of home zip code, is associated with mortality rates..$^{45,46,55,56}$ Absence of insurance coverage, so-called "self-pay" status, is a particularly adverse factor. ${ }^{24,43,55,56}$ In the pediatric age range, however, trauma patients admitted without insurance often acquire retroactive Medicaid coverage, and this coverage is registered in discharge data if the hospital stay is long enough. Patients with no insurance who die of their injuries tend to have relatively short lengths of stay in the hospital and may fail to acquire Medicaid coverage before discharge data are registered. Thus, the set of trauma mortalities is enriched in "self-pay" patients compared with survivors. To eliminate this bias, some studies of pediatric trauma, including the current study, analyze "self-pay" patients together with Medicaid beneficiaries. ${ }^{14,43,57}$

After controlling for economic status, several groups have reported the persisting significance of race as a predictor of trauma mortality. Falcone et al. studied trauma in infancy over a 10-year period at Cincinnati Children's Hospital. African-American infants had higher mortality rates from all mechanisms of injury, even after accounting for insurance coverage. ${ }^{13}$ In a follow-up study, this group analyzed mortality rates from abusive head injury in infancy. ${ }^{35}$ The investigators controlled for severity of injury by means of a CT scan grading system in addition to ISS and GCS scores. Again, black race was found to be associated with greater risk of mortality. Studies of pediatric trauma of all types using data from the NTDB have found consistently that both race and insurance status retain significance as predictors of mortality. ${ }^{24,48}$ In a study of severe TBI using 5 years of KID data, Piatt and Neff reported that both commercial insurance and white race retained significance as protective predictors in a multivariate model of mortality. ${ }^{43}$ Conflicting findings in other reports raise the possibility of geographic inhomogeneity in the importance of race as a predictor of pediatric trauma mortality. ${ }^{28,45}$ Little is known about disparities in functional outcomes in childhood trauma, but in an analysis of data from the National Pediatric Trauma Registry, after adjustment for severity and mechanism, Haider et al. found that black children with TBI were discharged from the hospital with greater degrees of disability, as measured by the WeeFIM (Functional Independence Measure for children). ${ }^{22}$
Economic status and race have been shown to be associated with disparities in the process of care in a variety of settings. In a study of emergency department visits for childhood TBI in Maryland, after adjustment for injury severity, McCarthy et al. found that children without insurance were less likely to be admitted than children with commercial insurance, who were in turn less likely to be admitted than children with Medicaid. ${ }^{36}$ Sabharwal et al. documented greater delays in management for extremity injuries among children with public insurance compared with children with private insurance. The latter arrived at the university hospital emergency department by ambulance at much higher rates than the former, who tended to arrive by private car. ${ }^{51}$ In a study of TBI in a large data set from the National Hospital Ambulatory Medical Care Survey, Mannix et al. found white race to be a predictor of CT scanning. ${ }^{33}$ Conversely, in a report from the Pediatric Health Information System, white infants with TBI were less likely to be evaluated for suspected abuse than black or Hispanic infants. ${ }^{57}$ Data from the 2000 KID suggest that both race and payor affect selection of treatments for pediatric long-bone fractures.$^{53} \mathrm{In}$ another study from the KID, admissions of children with severe TBI were more likely to be coded for intracranial pressure monitors if they were white, had commercial insurance, or lived in a relatively wealthy zip code. ${ }^{43}$ Children from wealthy zip codes were also more likely to have undergone a major neurosurgical procedure. Similarly, after adjustment for clinical and access factors, the current study determined that children with better insurance were more likely to undergo spinal fusion than other children with spinal injuries. Whether children from disadvantaged backgrounds are undertreated or whether children with advantages are overtreated is an intriguing question, the answer to which must vary from one clinical setting to another.

Interventions to correct disparities in the processes of care must take the form of guidelines, policies, or protocols. In what the authors describe as "the first report of a successful policy-based intervention to decrease disparity in care," Rangel et al. described implementation of a guideline requiring skeletal surveys for all infants with unwitnessed head injuries.$^{47}$ Historically, black children had undergone radiographic screening more frequently than white children at the authors' institution. The guideline corrected this disparity without diminishing the diagnostic yield.

The weaknesses of studies based on registries and administrative databases are well known. Limitations in the scope of data collection, missing data, uncertain accuracy in the recording of data, and imprecision in the definitions of categories are obvious concerns that were mitigated to a degree in the current study by the use of 2 complementary data sets collected by different mechanisms for different purposes. Reformatting data collected in the past for new statistical analysis entails many subjective decisions that offer opportunity for injection of bias. The ideal investigation is driven by hypotheses developed before examination of the data. In the current study, hypotheses were formulated and tested as the data were explored. Again, this flaw was mitigated to a degree by confirmation in the KID of an observation developed first in the NTDB. 
The existence of racial and economic disparities in trauma outcomes is well established. Many of the causes lie far outside the scope of medical practice, but recent work, including the current study, has focused attention on disparities in the processes of care, which are the responsibility of the physician and surgeon. Guidelines, protocols, and the measurement of quality are the obvious remedies. Future research may demonstrate that such measures have the power to efface disparities as well as to improve health care outcomes.

\section{Conclusions}

The incidence of admissions for pediatric spinal injury and SCI varies regionally in the US. Mechanisms, patterns, and severities of injuries have important associations with age, race, and payor. In this study, greater risk of mortality after spinal injury among black patients and higher rates of spinal fusion among patients with better insurance were explained incompletely by consideration of clinical factors and disparities in access.

\section{References}

1. Apple JS, Kirks DR, Merten DF, Martinez S: Cervical spine fractures and dislocations in children. Pediatr Radiol 17:4549, 1987

2. Barber I, Perez-Rossello JM, Wilson CR, Silvera MV, Kleinman PK: Prevalence and relevance of pediatric spinal fractures in suspected child abuse. Pediatr Radiol 43:1507-1515, 2013

3. Bayless P, Ray VG: Incidence of cervical spine injuries in association with blunt head trauma. Am J Emerg Med 7:139-142, 1989

4. Bazarian JJ, Pope C, McClung J, Cheng YT, Flesher W: Ethnic and racial disparities in emergency department care for mild traumatic brain injury. Acad Emerg Med 10:1209_ 1217, 2003

5. Brown RL: Epidemiology of injury and the impact of health disparities. Curr Opin Pediatr 22:321-325, 2010

6. Brown RL, Brunn MA, Garcia VF: Cervical spine injuries in children: a review of 103 patients treated consecutively at a level 1 pediatric trauma center. J Pediatr Surg 36:11071114,2001

7. Chien LC, Wu JC, Chen YC, Liu L, Huang WC, Chen TJ, et al: Age, sex, and socio-economic status affect the incidence of pediatric spinal cord injury: an eleven-year national cohort study. PLoS ONE 7:e39264, 2012

8. Choudhary AK, Bradford RK, Dias MS, Moore GJ, Boal DK: Spinal subdural hemorrhage in abusive head trauma: a retrospective study. Radiology 262:216-223, 2012

9. Cirak B, Ziegfeld S, Knight VM, Chang D, Avellino AM, Paidas CN: Spinal injuries in children. J Pediatr Surg 39:607-612, 2004

10. de Amoreira Gepp R, Nadal LG: Spinal cord trauma in children under 10 years of age: clinical characteristics and prevention. Childs Nerv Syst 28:1919-1924, 2012

11. Dickman CA, Zabramski JM, Hadley MN, Rekate HL, Sonntag VK: Pediatric spinal cord injury without radiographic abnormalities: report of 26 cases and review of the literature. J Spinal Disord 4:296-305, 1991

12. Eleraky MA, Theodore N, Adams M, Rekate HL, Sonntag VK: Pediatric cervical spine injuries: report of 102 cases and review of the literature. J Neurosurg 92 (1 Suppl):12-17, 2000

13. Falcone RA Jr, Brown RL, Garcia VF: Disparities in child abuse mortality are not explained by injury severity. J Pediatr Surg 42:1031-1037, 2007
14. Falcone RA Jr, Martin C, Brown RL, Garcia VF: Despite overall low pediatric head injury mortality, disparities exist between races. J Pediatr Surg 43:1858-1864, 2008

15. Finch GD, Barnes MJ: Major cervical spine injuries in children and adolescents. J Pediatr Orthop 18:811-814, 1998

16. Firth GB, Kingwell SP, Moroz PJ: Pediatric noncontiguous spinal injuries: the 15-year experience at a level 1 trauma center. Spine (Phila Pa 1976) 37:E599-E608, 2012

17. Fujii T, Faul M, Sasser S: Risk factors for cervical spine injury among patients with traumatic brain injury. J Emerg Trauma Shock 6:252-258, 2013

18. Hackl W, Hausberger K, Sailer R, Ulmer H, Gassner R: Prevalence of cervical spine injuries in patients with facial trauma. Oral Surg Oral Med Oral Pathol Oral Radiol Endod 92:370-376, 2001

19. Hadley MN, Sonntag VK, Rekate HL, Murphy A: The infant whiplash-shake injury syndrome: a clinical and pathological study. Neurosurgery 24:536-540, 1989

20. Hadley MN, Zabramski JM, Browner CM, Rekate H, Sonntag VK: Pediatric spinal trauma. Review of 122 cases of spinal cord and vertebral column injuries. J Neurosurg 68:18-24, 1988

21. Hagen EM, Eide GE, Elgen I: Traumatic spinal cord injury among children and adolescents; a cohort study in western Norway. Spinal Cord 49:981-985, 2011

22. Haider AH, Efron DT, Haut ER, DiRusso SM, Sullivan T, Cornwell EE III: Black children experience worse clinical and functional outcomes after traumatic brain injury: an analysis of the National Pediatric Trauma Registry. J Trauma 62:1259-1263, 2007

23. Haider AH, Weygandt PL, Bentley JM, Monn MF, Rehman $\mathrm{KA}$, Zarzaur BL, et al: Disparities in trauma care and outcomes in the United States: a systematic review and metaanalysis. J Trauma Acute Care Surg 74:1195-1205, 2013

24. Hakmeh W, Barker J, Szpunar SM, Fox JM, Irvin CB: Effect of race and insurance on outcome of pediatric trauma. Acad Emerg Med 17:809-812, 2010

25. Hills MW, Deane SA: Head injury and facial injury: is there an increased risk of cervical spine injury? J Trauma 34:549-554, 1993

26. Hofbauer M, Jaindl M, Höchtl LL, Ostermann RC, Kdolsky $\mathrm{R}$, Aldrian S: Spine injuries in polytraumatized pediatric patients: characteristics and experience from a Level I trauma center over two decades. J Trauma Acute Care Surg 73:156-161, 2012

27. Holly LT, Kelly DF, Counelis GJ, Blinman T, McArthur DL, Cryer HG: Cervical spine trauma associated with moderate and severe head injury: incidence, risk factors, and injury characteristics. J Neurosurg 96 (3 Suppl):285-291, 2002

28. Howard I, Joseph JG, Natale JE: Pediatric traumatic brain injury: Do racial/ethnic disparities exist in brain injury severity, mortality, or medical disposition? Ethn Dis 15 (4 Suppl):S5-51-S5-56, 2005

29. Iida H, Tachibana S, Kitahara T, Horiike S, Ohwada T, Fujii $\mathrm{K}$ : Association of head trauma with cervical spine injury, spinal cord injury, or both. J Trauma 46:450-452, 1999

30. Katz JS, Oluigbo CO, Wilkinson CC, McNatt S, Handler $\mathrm{MH}$ : Prevalence of cervical spine injury in infants with head trauma. J Neurosurg Pediatr 5:470-473, 2010

31. Knox JB, Schneider JE, Cage JM, Wimberly RL, Riccio AI: Spine trauma in very young children: a retrospective study of 206 patients presenting to a level 1 pediatric trauma center. J Pediatr Orthop 34:698-702, 2014

32. Laham JL, Cotcamp DH, Gibbons PA, Kahana MD, Crone KR: Isolated head injuries versus multiple trauma in pediatric patients: do the same indications for cervical spine evaluation apply? Pediatr Neurosurg 21:221-226, 1994

33. Mannix R, Bourgeois FT, Schutzman SA, Bernstein A, Lee LK: Neuroimaging for pediatric head trauma: do patient and 
hospital characteristics influence who gets imaged? Acad Emerg Med 17:694-700, 2010

34. Martin BW, Dykes E, Lecky FE: Patterns and risks in spinal trauma. Arch Dis Child 89:860-865, 2004

35. Martin CA, Care M, Rangel EL, Brown RL, Garcia VF, Falcone RA Jr: Severity of head computed tomography scan findings fail to explain racial differences in mortality following child abuse. Am J Surg 199:210-215, 2010

36. McCarthy ML, Serpi T, Kufera JA, Demeter LA, Paidas C: Factors influencing admission among children with a traumatic brain injury. Acad Emerg Med 9:684-693, 2002

37. Michael DB, Guyot DR, Darmody WR: Coincidence of head and cervical spine injury. J Neurotrauma 6:177-189, 1989

38. Mohseni S, Talving P, Branco BC, Chan LS, Lustenberger $\mathrm{T}$, Inaba K, et al: Effect of age on cervical spine injury in pediatric population: a National Trauma Data Bank review. J Pediatr Surg 46:1771-1776, 2011

39. Mortazavi MM, Dogan S, Civelek E, Tubbs RS, Theodore N, Rekate HL, et al: Pediatric multilevel spine injuries: an institutional experience. Childs Nerv Syst 27:1095-1100, 2011

40. O'Malley KF, Ross SE: The incidence of injury to the cervical spine in patients with craniocerebral injury. J Trauma 28:1476-1478, 1988

41. Pang D, Pollack IF: Spinal cord injury without radiographic abnormality in children-the SCIWORA syndrome. J Trauma 29:654-664, 1989

42. Piatt JH Jr: Detected and overlooked cervical spine injury in comatose victims of trauma: report from the Pennsylvania Trauma Outcomes Study. J Neurosurg Spine 5:210-216, 2006

43. Piatt JH Jr, Neff DA: Hospital care of childhood traumatic brain injury in the United States, 1997-2009: a neurosurgical perspective. J Neurosurg Pediatr 10:257-267, 2012

44. Platzer P, Jaindl M, Thalhammer G, Dittrich S, Kutscha-Lissberg F, Vecsei V, et al: Cervical spine injuries in pediatric patients. J Trauma 62:389-396, 2007

45. Ramirez M, Chang DC, Bickler SW: Pediatric injury outcomes in racial/ethnic minorities in California: diversity may reduce disparity. JAMA Surg 148:76-80, 2013

46. Rangel EL, Burd RS, Falcone RA Jr: Socioeconomic disparities in infant mortality after nonaccidental trauma: a multicenter study. J Trauma 69:20-25, 2010

47. Rangel EL, Cook BS, Bennett BL, Shebesta K, Ying J, Falcone RA: Eliminating disparity in evaluation for abuse in infants with head injury: use of a screening guideline. J Pediatr Surg 44:1229-1235, 2009

48. Rosen H, Saleh F, Lipsitz SR, Meara JG, Rogers SO Jr: Lack of insurance negatively affects trauma mortality in US children. J Pediatr Surg 44:1952-1957, 2009

49. Ruge JR, Sinson GP, McLone DG, Cerullo LJ: Pediatric spinal injury: the very young. J Neurosurg 68:25-30, 1988

50. Rush JK, Kelly DM, Astur N, Creek A, Dawkins R, Younas S, et al: Associated injuries in children and adolescents with spinal trauma. J Pediatr Orthop 33:393-397, 2013

51. Sabharwal S, Zhao C, McClemens E, Kaufmann A: Pediatric orthopaedic patients presenting to a university emergency department after visiting another emergency department: demographics and health insurance status. J Pediatr Orthop 27:690-694, 2007

52. Schenarts PJ, Diaz J, Kaiser C, Carrillo Y, Eddy V, Morris JA Jr: Prospective comparison of admission computed tomographic scan and plain films of the upper cervical spine in trauma patients with altered mental status. J Trauma 51:663-669, 2001

53. Slover J, Gibson J, Tosteson T, Smith B, Koval K: Racial and economic disparity and the treatment of pediatric fractures. J Pediatr Orthop 25:717-721, 2005

54. Soicher E, Demetriades D: Cervical spine injuries in patients with head injuries. Br J Surg 78:1013-1014, 1991

55. Tilford JM, Aitken ME, Anand KJ, Green JW, Goodman AC, Parker JG, et al: Hospitalizations for critically ill children with traumatic brain injuries: a longitudinal analysis. Crit Care Med 33:2074-2081, 2005

56. Tilford JM, Simpson PM, Yeh TS, Lensing S, Aitken ME, Green JW, et al: Variation in therapy and outcome for pediatric head trauma patients. Crit Care Med 29:1056-1061, 2001

57. Wood JN, Hall M, Schilling S, Keren R, Mitra N, Rubin DM: Disparities in the evaluation and diagnosis of abuse among infants with traumatic brain injury. Pediatrics 126:408-414, 2010

\section{Correspondence}

Joseph H. Piatt Jr., Nemours Neuroscience Center, A I duPont Hospital for Children, 1600 Rockland Rd., Wilmington, DE 19803.email: jpiatt@nemours.org. 